\title{
Sistemas de Automação Residencial Construindo Hábitos Sustentáveis nos Moradores
}

Home Automation Systems Building Sustainable Concern in Households

\author{
> Felipe Ferraz de Miranda \\ Universidade Federal de Santa Catarina, Brasil \\ lipemirandasc@gmail.com \\ > James Miyamoto \\ Universidade Federal do Rio de Janeiro, Brasil \\ jamesmiya@terra.com.br
}

\author{
> José Ripper Kós \\ Universidade Federal do Rio de Janeiro \\ Universidade Federal de Santa Catarina, Brasil \\ josekos@ufrj.br
}

\begin{abstract}
This paper presents the interface of a Brazilian house automation system, departing from an analogy of sailing race instruments. It aims to demonstrate the potential of automation systems on the house performance and, more important, on impacting households for a more sustainable behavior. Sailing instruments have positively influenced results on experienced sailors' speed and ultimately have confirmed their observations on nature cycles. Our argument is that if research on race sailing instruments soon became available to other sailing boats, systems developed to the Solar Decathlon houses' academic competition could, and should, be accessible to a great number of home owners.
\end{abstract}

Keywords: Home Automation; supervisory interface; sustainability; sailing instruments; Solar Decathlon

\section{Introdução}

Sistemas de automação e informação tornaram-se relativamente baratos e começam a difundir-se rapidamente. Supervisórios de código aberto associados a placas de micro-controladores de baixo custo conectadas a sensores e atuadores possuem um potencial de serem aplicados em larga escala, mesmo em habitaçáo de baixa renda. No entanto, a maioria dos sistemas de automação residencial está restrita a casas caras e limitados a integrar algumas funçóes domésticas normalmente relacionadas à iluminação, ao condicionamento térmico, mídias e segurança. $\mathrm{O}$ uso desses sistemas para garantir um melhor desempenho e mais sustentabilidade nas residências ainda é uma raridade. $\mathrm{O}$ mesmo não acontece em edifícios industriais ou comerciais, quando o desempenho e a sustentabilidade dos seus edifícios garantem maior rentabilidade e lucros. Para estes casos, existem muito mais sistemas de controle e gerenciamento de edificaçôes que garantem a eficiência e conforto térmico através do gerenciamento do condicionamento, dos sistemas hidráulicos, etc. Embora igualmente úteis em residências, os sistemas residenciais são pouco explorados nessa direção. Estes sistemas poderiam incorporar ferramentas poderosas para proporcionar informaçóes atualizadas sobre o desempenho da casa, bem como dados meteorológicos que pudessem contribuir para decisóes e até mudanças de hábitos dos moradores. Além disso, eles podem apoiar uma compreensão a cerca do funcionamento da casa, que vem se perdendo ao longo da história, a medida que as nossas casas incorporaram novas tecnologias e ficaram mais complexas. Para proporcionar uma redução significativa do impacto ambiental, as casas não só devem ser tecnologicamente holística. Eles devem aparecer holística para seus usuários. $\mathrm{O}$ desempenho das casas depende muito de usuários e de sua conscientização. A redução do consumo de energia, por exemplo, depende tanto de tecnologias quanto das decisóes tomadas pelos usuários (Schipper, 1989; Socolow, 1978).

Vários autores defendem o edifício como um instrumento educativo (Orr, 1997; Rohwedder, 2004; Janda, 2011) Orr (1997) identifica a capacidade pedagógica dos edifícios para ensinar - ou "desensinar" - os seus usuários sobre a desconexão da sociedade com o ambiente. No entanto, ele também oferece sugestóes para explorar edifícios como ferramentas de aprendizagem sustentável. Kathryn Janda (2011) reconhece também que os profissionais da construçáo, especialmente arquitetos, devem conduzir a mudanças relevantes para redução de energia relacionadas ao comportamento dos usuários. Segundo ela, a educação é o instrumento-chave.

O projeto de edificaçóes e suas tecnologias possuem o potencial de envolver e educar seus usuários. David Orr (1997) apresentou o argumento de que os nossos edifícios desperdiçam um potencial de refletir uma agenda oculta embutida em suas escolhas de projeto. Ele perguntou se "Através de um melhor projeto é possível ensinar nossos alunos [usuários] que os nossos problemas podem ser resolvidos e que eles estáo conectados a um sistema mais amplo de vida?" Seguindo o conselho, os arquitetos deveriam se preocupar sobre como os moradores percebem e entendem suas casas. As casas, como qualquer edifício, deveriam ser adaptáveis a diferentes condiçóes ambientais e seus moradores deveriam igualmente desejar que elas estejam bem reguladas para cada condição. 
Nessa direção, os velejadores podem nos ensinar sobre a motivação de ter seu barco perfeitamente regulado. A conexão entre veleiros e edifícios foi apresentada por diferentes autores, com uma ampla gama de abordagens (Murcutt, 2008; Burry, 2013). Uma casa pode ser regulada de uma maneira similar à forma como os velejadores ajustam e planejam suas estratégias de regata. Velejadores de regatas possuem uma forte ligaçáo com o ambiente natural. Seu sucesso depende da capacidade de compreensão do funcionamento do barco e das variáveis ambientais e seus ciclos.

Burry, Aranda-Mena, Alhadidi, Leon e Williams (2013) afirmam que "em comparação com a arquitetura, o desempenho é mais transparente em esportes de alto desempenho, tais como vela, onde fica claro que velocidade é bom”. Embora sua abordagem para a relação entre regatas e arquitetura possua uma perspectiva diferente, gostaríamos de usar essa afirmativa para reforçar nosso argumento.

Os veleiros de alto desempenho incorporam uma grande variedade e complexidade de tecnologias. Estas tecnologias apoiam as conexóes entre os velejadores e o ambiente natural e o desempenho do barco. $\mathrm{O}$ argumento deste artigo é que sensores, atuadores e automação residencial e interfaces de sistemas de automação devem funcionar de forma semelhante às tecnologias desenvolvidas para veleiros de regata. Eles devem fornecer dados atualizados dos sistemas e do desempenho da casa, das condiçôes meteorológicas associados a informaçóes de previsão do tempo. Estes sistemas podem desempenhar várias funçóes automatizadas voltadas para a conscientização dos moradores. Várias dessas tecnologias surgiram a partir de pesquisas voltadas para regatas de alto desempenho e campanhas de alto custo, como a mais famosa "America's Cup".

"Durante toda a década de 1980 a Copa América foi disputada em barcos de doze metros, tendo avanços significativos feitos na construçáo do casco, tecido da vela, layout dos painéis e nos painel, e nos sistemas de instrumentos. Mas, talvez mais do que as outras inovaçôes, os instrumentos começaram a mudar a forma como os barcos são velejados. As informaçóes sobre os ângulos do vento e velocidade do barco ficaram melhores do que nunca, mas ser capaz de fazer cálculos que poderiam indicar a eficiência com que o barco estava sendo navegado era o que estava mudando o jogo para os melhores velejadores do mundo". (Ockam, 2013)

A performance de uma casa é muito diferente dos barcos de regata. Este último precisa chegar ao destino antes dos outros concorrentes. A velocidade do barco não é o único parâmetro para definir o vencedor, mas é certamente decisivo e velejadores devem sempre procurar a melhor velocidade em condiçóes ou estratégias específicas. Em uma casa, os moradores devem alcançar um conforto sustentável.

Barcos de cruzeiro não precisam vencer seus concorrentes, mas são altamente influenciados pelas inovações desenvolvidas pela vela de alto desempenho. Estas tecnologias fornecem aos velejadores de cruzeiro uma combinação do desempenho do barco, dados meteorológicos e posição geográfica. Esses instrumentos não afastam os velejadores de uma consciência ambiental, como as tecnologias fizeram no passado com os edifícios. Pelo contrário, elas facilitam a compreensão dos dados ambientais naturais como uma rede integrada. As residências primitivas foram desenvolvidas como dispositivos adaptados e adaptáveis às condiçóes ambientais. Seus moradores podiam sentir o vento mudar de direção e perceber as mudanças através das cores e cheiros. O tempo poderia ser previsto e a casa preparada para condiçóes extremas. As tecnologias dos edifícios proporcionaram casas confortáveis, melhor protegidas de condiçóes climáticas extremas, menos dependentes dos ciclos ambientais, mas também mais dependentes de energia.

Estamos tão desconectados dos ciclos ambientais que é uma tarefa difícil envolver os usuários em hábitos mais sustentáveis. Por isso, a forma como os veleiros integram suas tecnologias pode ensinar-nos a entender melhor os dados ambientais, a fim de reconhecer o nosso lugar na Terra e saber adaptar melhor os nossos hábitos aos ciclos ambientais. A maioria de nossas tecnologias domésticas têm sido desenvolvidos em épocas em que a energia e o ambiente não eram uma grande preocupação. Não precisamos nos livrar da tecnologia, mas desenvolver sistemas mais eficientes, capazes de conectar melhor os nossos edifícios e seus usuários com o ambiente natural.

Apresentamos a seguir, o desenvolvimento de um sistema de automação residencial para uma casa brasileira e especialmente sua interface gráfica, elaborada para facilitar a compreensão do funcionamento da casa e seu desempenho, apoiando decisóes sustentáveis dos moradores, como os instrumentos de barcos de cruzeiro, desenvolvidos a partir de regatas de alto desempenho. $\mathrm{O}$ sistema de automação da Casa Florianópolis também teve origem no sistema desenvolvido para a primeira participação brasileira na reconhecida competiçáo acadêmica Solar Decathlon. (Team Brasil, 2012)

\section{A Casa Florianópolis}

A Casa Florianópolis localiza-se próxima à praia, na Ilha de Santa Catarina, no sul do Brasil. Esta regiáo possui poucas elevaçóes e temperaturas ligeiramente inferiores ao interior da ilha. A regiáo possui um índice de precipitação anual de $1600 \mathrm{~mm}$, umidade relativa anual de $85 \%$ e cerca de 140 dias de chuva por ano (Lamberts et. al., 2010) A água da chuva é, portanto, um importante recurso a ser aproveitado. O posicionamento da piscina na frente de toda a sala, com uma parede de bambus ao fundo, que ao crescer, protege da visão do vizinho e permite que a água da chuva caindo na piscina seja desfrutada pelos moradores da casa. Mesmo para uma casa de praia, a vivência da chuva é um aspecto importante e pouco considerado. A piscina permite ainda que nos dias de sol a casa esteja mais clara e se transforma nos vários dias com muito vento. Ela amplifica as mudanças climáticas, aproximando os moradores dos ciclos da natureza. Ela é também a principal fonte de captação da água da chuva.

O conforto interno é garantido através de duas estratégias principais: grande quantidade de massa térmica isolada do exterior e ventilaçáo cruzada na direçáo dos principais ventos da regiâo (Norte, Nordeste e Sul). Estas estratégias devem ser gerenciadas pelos moradores, evitando abrir muito a casa em horários de extremo calor. Nos dias mais quentes deve-se abrir mais a casa à noite e nos dias frios, manter as janelas mais fechadas, deixando o sol entrar. A fachada principal, voltada para a piscina, é orientada 


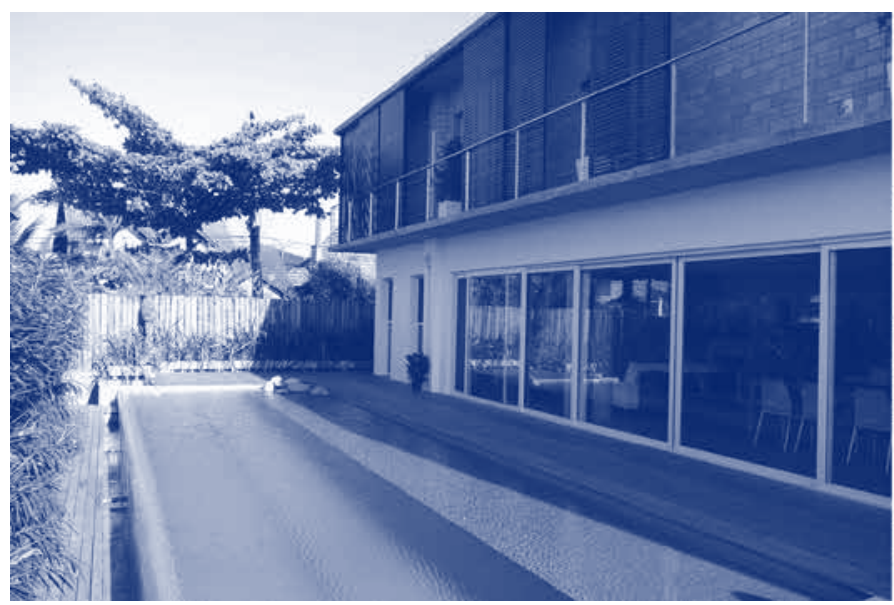

Figura 1: Casa Florianópolis.

para N/NE, com grandes janelas e portas que garantem ampla iluminação e insolaçáo nos meses mais frios. Painéis de madeira na sacada superior garantem o sombreamento dos quartos e, quando superpostos, oferecem mais privacidade para os quartos. A varanda superior oferece proteção para a insolação inadequada no verão e permite sua entrada no inverno.

\section{O sistema de automação e informação residencial}

O supervisório open source de controle e aquisição de dados (SCADA) é um componente crítico para o sucesso do Sistema de Automação e Informaçáo Residencial (SAIR) da Casa Florianópolis. O supervisório open source ( $\mathrm{ScadaBR}$ ) foi desenvolvido na Universidade Federal de Santa Catarina para uma grande variedade de usos. A primeira versão do sistema foi lançada há seis anos e seus autores buscam mantê-lo o mais amplo possível. Escolher uma ferramenta de código aberto foi um dos objetivos do nosso grupo de pesquisa. Ele aplica-se diretamente a um dos objetivos do projeto de pesquisa, que procura testar possibilidades para soluçóes de automação sustentáveis para habitaçáo de baixa renda.

O sistema SCADA integra os componentes controlados com diferentes sensores e dados meteorológicos e uma interface gráfica está aperfeiçoada para facilitar a visualização de dados, apoiando a escolha dos moradores mais sustentáveis (Haeffner e Casalegno, 2009). A rede é baseada na tecnologia I2C, com cerca de 700 metros de cabo Cat5e para conectar botóes, sensores, teclados e módulos de extensão à distância. A topologia suporta as interligaçóes necessárias reduzir as respostas de atraso. Cada módulo ou sensor adicional no bus acrescenta mili-segundos para a digitalizaçáo completa da rede. $\mathrm{O}$ projeto deve ser dimensionada para atender às expectativas de tempo de resposta, que são menos de $275 \mathrm{~ms}$. O atraso do sistema é ideal perto de $150 \mathrm{~ms}$, para dar uma sensação de feedback instantâneo. O sistema funciona em um Controlador Lógico Programável desenvolvido localmente (PLC). O controlador principal integra todos os sensores e atuadores de toda a casa. Um programa de baixo nível (LADDER) é executado dentro do controlador, que dá autonomia para as tarefas repetitivas e cruciais, tais como abrir e fechar as janelas motorizadas de acordo com o clima local atual.

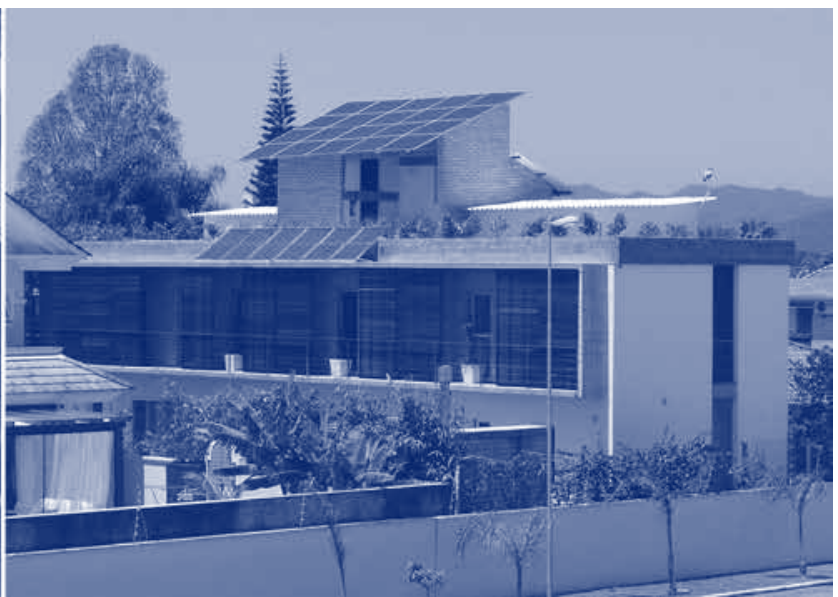

Vários sistemas passivos são controlados pelo sistema de automação ou apoiados pelo supervisório através de sensores e dados meteorológicos. Entre eles, estão três janelas motorizadas, reguladas pelo sistema de automaçáo, voltadas para a direção sul, acima do telhado verde, com o objetivo de facilitar a ventilação cruzada e extrair o ar quente. A estação meteorológica e outros quatro sensores de temperatura medem a temperatura exterior e nos diferentes níveis da casa, indicando o desempenho da casa e os momentos adequados para que as janelas sejam abertas. Além disso, as janelas fecham automaticamente quando a chuva é combinada com vento sul, para evitar a entrada de água da chuva. As janelas das casas oferecem diversas alternativas para ventilaçáo cruzada, que também são realçadas na interface de supervisão e verificadas pelo sensor magnético localizado nas molduras das janelas.

A visualização de dados é um dos principais focos do trabalho e é fundamental para uma utilização eficaz e sustentável dos dados de desempenho da edificação e climáticos. Se por um lado é importante unir, em uma única interface, a maior parte dos controles e dados da casa, por outro lado eles tornam a interface do supervisório cada vez mais complexa. Assim, é importante que os dados sejam organizados por sua importância hierárquica, relacionando-a com as formas de compreendê-la a partir dos diferentes moradores. (Bermudez e Agutter, 2005)

A interface integra informações numéricas, tais como temperatura do ar, com gráficos SVG (Scalable Vector). Portanto, pode-se rápida e facilmente distinguir a variação de temperatura em diferentes áreas da casa, bem como a temperatura exterior. A interface é desenvolvida para ser perfeitamente visualizado em uma tela de computador ou iPad, e nosso próximo passo será desenvolver uma interface reduzida e simplificada para smart phones. Ela apresenta a casa em três imagens de fundo geradas a partir de um modelo 3D gerado no Revit. As imagens de fundo usam o mesmo ponto de vista de perspectiva e variam entre uma imagem externa, e dois cortes diferentes (Figura 2), para facilitar a visualização das informaçóes de cada seção. Os dados são organizados em quatro grupos principais: energia, água, clima e segurança e as imagens de fundo alternam-se de acordo com o item do menu.

Algumas poucas iniciativas foram desenvolvidas com foco em sistemas de automação e informação para moradias mais sustentáveis 


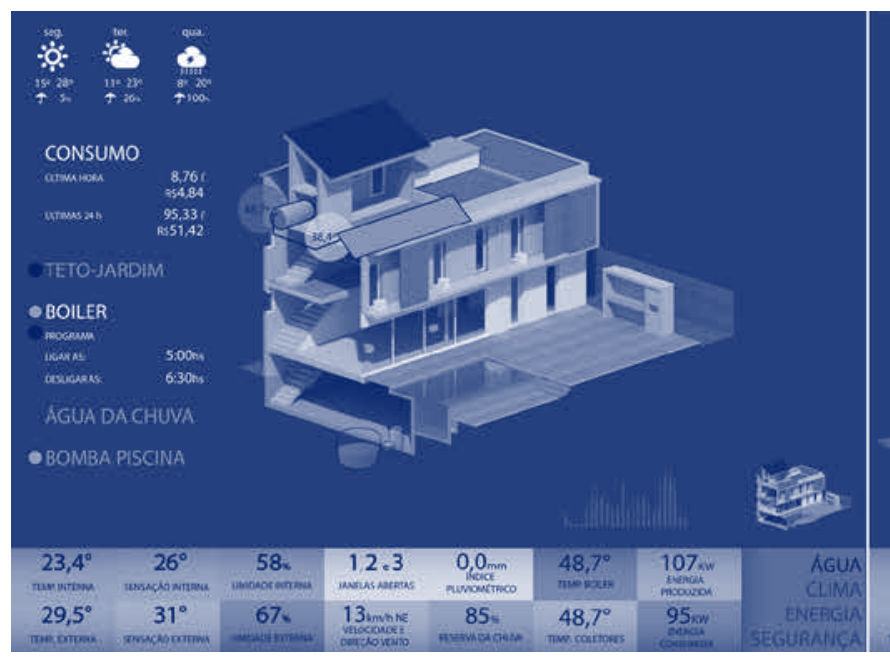

Figura 2: Telas da interface do supervisório open souce (SCADABR) da Casa Florianópolis.

(Kotsopoulos, et al 2012;. Paetz, Dutschke, e Fichtner, 2012). No entanto, a maioria dos sistemas atuais ainda é direcionada para automatizar tarefas de rotina, como ligar um conjunto de lâmpadas simultaneamente, a fim de simplificar atividades domésticas diárias ou orientadas para o lazer, geralmente por meio de integração de mídia. A redução dos custos de equipamentos eletrônicos sugere um potencial importante para sistemas de automação sustentáveis, mesmo para habitaçóes de baixa renda. Microcontroladores de baixo custo, tais como Arduino são capazes de realizar tarefas simples, mas relevantes nesta área, através da conexão de sensores e atuadores.

A maioria das tecnologias residenciais voltadas para o aumento da eficiência energética possui um impacto limitado, se não contar com a contribuição dos usuários. Para isso, a educação é uma fonte essencial para a promoção de mudanças significativas. A relação entre tecnologia e usuários domésticos é decisiva para o desempenho e sustentabilidade da casa. Algumas tarefas podem ser automatizadas, mas as açôes mais relevantes são as decisóes conscientes e sustentáveis tomadas pelos usuários (Darby, 2006). Mesmo as casas construídas para as competiçóes Solar Decathlon precisa de um usuário bem informado capaz de regulá-la de forma eficiente.

\section{Educando os moradores}

Janda argumenta que as decisóes que afetam a maneira como as pessoas usam seus edifícios e que levam a um consumo elevado referem-se principalmente ao déficit de informaçáo e aos seus próprios hábitos de vida, práticas e normas. (Janda, 2011) Partimos de uma analogia com instrumentos de regatas para demonstrar o potencial de sistemas de automação sobre o desempenho casa e, principalmente, sobre o comportamento das famílias. À semelhança das regatas mais importantes, como a Copa América, a competição Solar Decathlon tem proporcionado experiências relevantes e inovadoras em automaçáo residencial voltadas para desempenhos sustentáveis. Nosso argumento é que, se a pesquisa de instrumentos para a America's Cup logo tornou-se disponível para outros barcos à vela, os sistemas desenvolvidos para as casas Solar Decathlon

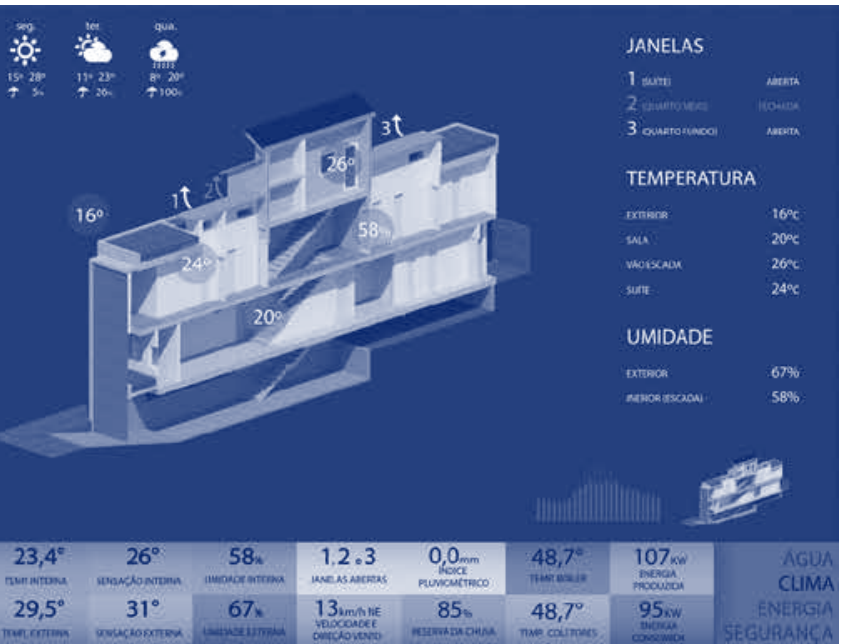

podem, e devem, ser acessíveis a um grande número de moradores. O sistema de Florianópolis Casa partiu do sistema da casa brasileira Ekó House para o Solar Decahtlon Europe 2012, baseando-se no seu conceito e em algumas de suas características. Em vez de esconder as complexidades de todos os sistemas das casas, ele busca apresentar a compreensão do funcionamento da casa, envolvendo e desafiando os moradores para um melhor desempenho. Argumentamos que sistemas de automação residencial e suas interfaces possuem um potencial relevante que não é explorado pelo mercado. A principal contribuição da interface da Casa Florianópolis para envolver os usuários é através de gráficos históricos, dados traduzidos para as cores e os renderings $3 \mathrm{D}$ de cortes da casa. Apreender o impacto de mudanças de hábitos no desempenho casa não é uma tarefa fácil e é fundamental que exista um engajamento dos usuários.

Os instrumentos náuticos não reduzem as conexôes entre bons velejadores e o ambiente natural. Pelo contrário, eles garantem aos velejadores experientes, uma confirmação de suas observaçóes empíricas da natureza. Os moradores urbanos contemporâneos perderam muito de suas conexóes com o ambiente natural. As tecnologias desenvolvidas ao longo dos últimos séculos reduziram a necessidade de adaptar suas vidas aos ciclos naturais. A padronização e internacionalização das edificações também têm contribuído para esta tendência. Estudos realizados em comunidades primitivas destacam essas observaçóes. Estes moradores desenvolveram suas casas e a forma como eles as habitam com base em observaçóes empíricas. Seus hábitos estão diretamente associados ao desempenho das suas moradias, particularmente em casos de condiçóes climáticas extremas. Os velejadores experientes não perderam, ao longo da história, a sua capacidade de compreender os ciclos naturais. Buscamos através deste trabalho, defender que estes sistemas têm adicionado precisão e confirmação de observaçóes dos velejadores e que eles poderiam proporcionar conexóes semelhantes que os habitantes urbanos carecem.

\section{Agradecimentos}

Os autores agradecem ao Ministério da Ciência, Tecnologia e Inovação (CNPq) e Ministério da Educação (CAPES) pelo apoio para o desenvolvimento desta pesquisa. 


\section{Referências}

Bermudez, J. and Agutter, J. (2005). Arquitectura informática: desafio, respuesta y potencial. arquiteturarevista, 1(1), Retrieved from: <http://www.arquiteturarevista.unisinos.br/index. php? $=1 \& s=9 \& a=2>$ Accessed 18, OC-tober 2013).

Burry, J.; Aranda-Mena, G.; Alhadidi, S.; Leon, A.; Williams, M. (2013). Design Trade-off: Sailing as a vehicle for modelling dynamic trade-off design, in J. Burry, Designing the dynamic: High-performance sailing and real-time feedback in design, Melbourne Books, Melbourne, 17-23.

Darby, S. (2006). The Effectiveness of Feedback on Energy Consumption: A Review for DEFRA of the Literature on Metering Billing and Direct Displays, Rep. No. Environmental Change Institute, University of Oxford. Oxford.

Haeffner, M and Casalegno, F. (2009). How does a visual monitoring system foster sustainable behavior?., International Journal of Instructional Technology and Distance Learning, 6(10), pp. 27-35

Janda, K. B. (2011). Buildings don't use energy: people do, Architectural Science Review, 54(1), 15-22.

Kotsopoulos, S, Casalegno, F, Ono, M and Graybill W. (2012). Window Panes Become Smart: How responsive materials and intelligent control will revolutionize the architecture of buildings, Proceedings of The First International Conference on Smart Systems, Devices and Technologies (SMART 2012), pp. 112-118.

Lamberts, R.; Ghisi, E.; Pereira, C.; Batista, J. (eds.). (2010). Casa eficiente : Bioclimatologia e desempenho térmico, UFSC/ LabEEE, Florianopolis.
Lynn G. and Gage M. F. (eds). (2011). Composites, Surfaces, and Software: high Performance Architecture, Yale School of Architecture, New Haven.

Murcutt, G. And Thompson, P. (2008). Transcripts from TV interview to ABC Talking Heads, Retrieved from: http://www. abc.net.au/tv/talkingheads/txt/s2256196.htm> Accessed 9, December 2013)

Ockam Instruments, Inc. (2013). Twelve Meter Yachts and their Sailing Instruments". Retrieved from: <http://ockam. com/2013/02/23/twelve-meter-yachts/> Accessed 9, December 2013)

Orr, D. W. (1997). Architecture as pedagogy II, Conservation biology, 11(3), pp. 597-600.

Paetz, AG, Dütschke, E and Fichtner, W. (2012). Smart Homes as a Means to Sustainable Energy Consumption: A Study of Consumer Perceptions, Journal of Consumer Policy, 35(1), pp. 23-41.

Perez-Lombard, L, Ortiz, J, and Pout, C. (2008). A review on buildings energy consumption information', Energy and buildings , 40(3), pp. 394-398.

Rohwedder, R. (2004). The Pedagogy of Place: The Environmental Technology Center at Sonoma State University, Higher Education and the Challenge of Sustainability, pp. 293-304. Springer Netherlands.

Schipper, L, Bartlett, S, Hawk, D, and Vine, E. (1989). Linking life-styles and energy use: a matter of time?, Annual review of energy, 14(1), 273-320.

Socolow, R.H. (1978). Saving energy in the home. Princeton's Experiments at Twin Rivers, Cambridge, MA, Ballinger. 